\title{
LA FLUORESCENCIA VULVAR EN EL DIAGNOSTICO Y TRATAMIENTO DE LA AMENAZA DE ABORTO
}

(Tomado de "Procedings of the first world congres on Fertility and Sterility").

\section{Por Sidney Margolese}

El fenómeno de la fluorescencia vulvar ha sido ya señalado en varias publicaciones y verificado por algunos autores.

Cuando la vulva se examina bajo la lámpara ultravioleta, se observan multitud de colores que tienen relación íntima con el momento endocrino de la mujer. En la pubertad no se presentan cambios de ninguna naturaleza, después de la menarquia cuando existe ya influєncia estrogénica marcada, predomina el color verde en la fluorescencia. Cuando la actividad estrogénica crece, o cuando se administran preparados de esta naturaleza, se forman áreas periféricas de fluorescencia rojiza que invaden poco a poco toda la superficie vulvar.

Una vez hace su aparición la Progesterona, natural o arti_ ficialmente se presenta un aumento de la fluorescencia rojiza que se intensifica tanto que llega al púrpura, razón por la cual se aso_ cia esta coloración con el metabolismo de la Progesterona.

Analizando estos hechos, concluye el autor, basado en la observación de 70 embarazos, que la fluorescencia dominante durante el embarazo es de color púrpura, y que la roja jamás se' presenta en los casos normales. La fluorescencia roja se observa en la amenaza de aborto, habiendo podido relacionar el tratamiento con Progesterona o con estrógenos-progesterona con el retorno a la fluorescencia púrpura.

Finalmente anota el autor que la observación de los cambios de la fluorescencia vulvar puede resultar útil en el manejo de las conductas en la amenaza de aborto y en los trastornos hormonales ováricos.

R. R. G. 